\title{
Career Development Program for Junior High School English Teachers
}

\author{
Blademer Manalo $^{1 *}$, Larry Ojales $^{2}$ \\ ${ }^{I}$ Teacher III, Department of Education, Coral na Munti NHS, Batangas, Philippines \\ ${ }^{2}$ Master Teacher, Department of Education, Taal Senior High School, Batangas, Philippines \\ *Corresponding author: blademer.manalo001@deped.gov.ph
}

\begin{abstract}
Despite the existence of some policies to promote career growth, still the fact remains that many teachers face problems about this matter. This study aimed in proposing a career development program by describing the profile of junior high school English teachers and showing its association to the extent of their commitment and responsiveness to instruction, research and community service. Moreover, it also identifies both issues related to career development. In order to attain the objectives, this research endeavour utilized descriptive method of research using questionnaire as data gathering instrument. Findings showed that teachers responded to the call of continuing professional development by earning post graduate degrees but had few related trainings and limited memberships. In addition, they showed commitment and responsiveness only on a moderate extent with regards to research and community service. The data further proved that instruction depends on training and development while research depends on membership to professional organization. It also stressed the findings that an organized and well-planned career development contributes to individual and organizational growth. However, issues and challenges may occur in the workplace if the administration fails to prioritize this. There is also a need for more training and memberships in various organizations and often participation in professional development activities is also recommended.
\end{abstract}

Keywords: Career development, Community engagement, Organizational growth, Responsiveness.

\section{Introduction}

Searching for a stable career in a certain organization or a specific workplace is a usual scenario for many individuals. Related to it, Jones, George and Hill (2010) viewed career as the sum of total work-related experiences throughout a person's life. Career becomes the most important connection between an individual and organization. It is composed of the person's working experience gained while performing different jobs and moving between diverse positions, but it is also fulfilled by achieving greater responsibility, power and progression on his/her career path.

In line with this, Archer (2019) proved that career offers fulfillment personally and professionally that a job does not. A career becomes part of an employee's identity as he gains more specialized skills and networks with a wider group of professionals. Young, talented and well educated and skilled professionals put their career and development among the most important segments of their life, and they stay in certain position until they see perspectives for personal and career development. Career encompasses experience, education and future path within a particular industry. With this, career growth factors influence commitment in an additive rather than a multiplicative manner (Weng \& Mcelroy, 2010).

On the other hand, Stevenson (2019) emphasized the importance of career pathing. This refers to the process by which the teacher and, usually, the administrator chart a path toward the employee's future development goals. The destination, as well as the steps, experience, and development needed to get there are included. This helps drive consistency so that as people develop, they have clarity on the knowledge, the skills, and behaviors that are required for them to succeed at different goals or different levels. Career pathing can be a critical component in employee engagement and employee retention. Schools that assist teachers in developing this career path ensure the employee feels a deeper connection to the organization and thus, will continue to work for the school in the years to come.

It is for this reason that public institutions must be aware of the fact that creating stable and fruitful future growth and career will be possible only with the help and support of human resources. The relationship between the employees and the higher officials in the workplace has changed in a way that both parties want to derive benefit from that relationship (Craig, 2017). Teachers that work to build a strong and positive relationship with schools will grow as professionals and give back tenfold. It is for this reason that individual's growth and satisfaction are directly linked to career development that is why it should be managed by the individual and not solely left to the employer. It helps an individual to grow not only professionally but also personally. Part of this growth is learning new skills like leadership, time management, good governance, communication management, and team management. It supports an employee develop and shape their career in the future.

Despite the existence of some stated laws and policies that promote career development among teachers, still the fact remains that not all personnel are experiencing its good impact as evident in the report of Gonong (2018) about addressing 
teacher professional development issues among in-service teachers. It revealed that the need for professional training and learning was on top of the imperatives for teachers. They emphasized the importance of enhancing their practice. It also highlighted that among the issues presented like learner discipline, teaching strategies, instructional resources and many more, still professional training and learning is the most urgent thing for them.

Likewise, it also showed that a large proportion of teachers felt they needed more in-service training opportunities. The data further stresses that professional development opportunities currently offered to teachers frequently fail to meet even minimum levels of quality and fall short of what teachers want and need. In addition, systems at the school level to support teachers and identify their professional development needs are not working well. And lastly, utilization of budget allocated for human resource training and development is often low, amounting to only 57 percent of the budget in 2014 .

Moreover, it also quoted the teachers' sentiments on the lack of time for professional learning like attending graduate studies to enhance teaching practice due to accomplishments of reports and other tasks and that teachers were not fully trained in the changes of curriculum to meet its requirement. Furthermore, a one-week seminar was not enough based on the teachers perspective.

Moreover, not all teachers were given opportunities to attend training seminars especially those that are in the far-flung areas. Getting into seminars was also difficult according to them because they were expected to be at school to teach and guide students at all times. Taking units for MA or attending training would mean that students will be left unattended as there is no system to cover for teachers who aren't around for official business. These issues of teachers' performance in relation to the teaching qualification, characteristics and competence were also the main focus of Lucky (2013).

With this, the researcher wanted to focus his study on career development of Junior High School teachers. Seeing some of his colleagues in the school facing same challenges and problems about the aforementioned issue made him decided to venture on this timely topic supported by the claim of JobStreet Philippines that the top reasons for Filipino employee dissatisfaction are career development, management quality and cultural social responsibility.

\section{Methodology}

In order to attain the objectives, the researcher utilized the descriptive method of research. The respondents involved in this study were secondary English teachers in Junior High School of the four schools division offices in Batangas including Division of Lipa City, Division of Tanauan City, Division of Batangas City and Division of Batangas Province. The size of sample was determined using Slovin's formula at five percent margin of error and was selected through cluster sampling using proportionate allocation. Data for the study were collected through online questionnaire.

The distribution of Junior High School English respondents is shown in table 1 .

Table 1

Respondents of the study

\begin{tabular}{|l|l|l|}
\hline Division & Population & Sample \\
\hline Batangas Province & 754 & 204 \\
Batangas City & 122 & 33 \\
Lipa City & 123 & 33 \\
Tanauan City & 71 & 20 \\
\hline Total & 1070 & 291 \\
\hline
\end{tabular}

\section{Objectives}

This study focused in proposing a career development program for Junior High School English teachers in the Province of Batangas.

Specifically, it aimed to attain the following research targets:

1. Describe the profile of the teachers with regards to:

1.1 highest educational attainment;

1.2 teaching experience;

1.3 training and development; and

1.4 membership in professional organization.

2. Determine the extent of commitment and responsiveness in teaching along with the following dimensions:

\section{1 instruction;}

2.2 research; and

2.3 community service.

3. Show how the extent of commitment and responsiveness relate to selected profile variables.

4. Identify opportunities and prospects for individual and organizational growth.

5. Identify issues and challenges related to career development.

6. Propose a career development program for Junior High School English teachers.

\section{Findings}

\section{A. Profile of junior high school English teachers}

\section{1) Educational attainment}

Majority of the respondents already continued their post graduate studies in support with the concept of continuing professional development through earning master's and doctorate degree and for promotion purposes. On the other hand, there were still some teachers whose highest educational attainment remains to be baccalaureate degree which was associated with limited financial resources and lack of time for professional learning.

\section{2) Teaching experience}

Many of the respondents are on their competent level in the service and are considered as proficient teachers according to results-based performance management system manual for teachers. In addition, many of the teachers teaching this specific discipline have already been in the teaching profession for quite a long time due to their dedication, commitment and passion in 
shaping young minds as supported by their length of service.

3) Training and Development

There were only few teachers who had trainings on their field of specialization. The data also supported that many teachers are still lacking for related trainings to the subject they are handling particularly in English which covers various domains including the macro-communication skills.

\section{4) Membership in professional organization}

The data revealed that many of the English teachers remain moderately active in having membership in a specific organization. Moreover, majority of the respondents only have one or no membership at all in any of the existing professional organization in the department or even outside of the agency.

B. Extent of commitment and responsiveness in instruction, research and community service

\section{1) Instruction}

The data proved that the extent of commitment and responsiveness of English teachers in terms of instruction was to a great extent. This signified that they are performing well when it comes to their primary role which is to deliver the teaching-learning process. With this, they exhibited their functional competencies in this area to sustain the delivery of quality, accessible, relevant and liberating basic education to the learners.

Commitment in the manifestation of content knowledge and pedagogy as part of instruction was also seen to a great extent as teachers applied knowledge within and across curriculum teaching areas. Relative to this, teachers utilized a range of teaching strategies in enhancing learners' achievement in literacy and numeracy skills and were also able to integrate key content elements with other subject areas in the discussion of the lesson.

Findings also on the other aspect of instruction like securing learning environment and diversity of learners was exhibited to a great extent. Relative to this, they managed classroom structure to engage learners in meaningful exploration and discovery of the concepts of the subject. Learning-focused environment was also ensured through managing learner behavior by performing mentoring and counseling and by applying positive and non-violent discipline to avoid possible conflict that may arise.

In terms of curriculum planning, the data signified that teachers select, develop and organize appropriate teaching and learning resources. They also showed commitment and responsiveness in choosing suitable approaches to attain the objective of the lesson. Through this, they were able to ensure that the curriculum responds to the need for quality citizens.

Lastly, it also revealed that assessment and reporting are demonstrated to a great extent. Proof to this is the commitment of teachers in monitoring and evaluating learners' progress through various forms of evaluation. Feedbacks on students' learning outcomes are also communicated properly to the parents and guardians to keep them updated on the status of their children in the school.

\section{2) Research}

The extent of commitment and responsiveness of the respondents with regards to research is only on a moderate extent due to limited knowledge on the processes and methods of research. This was also associated with lack of willingness and motivation in this undertaking.

Despite of this, they are responsive to a moderate extent in accepting comments and suggestions in conducting research to improve skills and willing to collaborate with the school's research committee to produce more studies that will address issues and problems in various areas. In support with this, they showed openness in attending research writing, helping other teachers and sharing knowledge about it. They are also committed in adhering to the ethics of research writing.

Furthermore, the data also ascertained that many of the respondents would communicate their best practices among peers and would promote the culture of research to a moderate extent. Conducting in-depth studies on instructional problems as basis for possible intervention program and presenting findings, conclusions and recommendations in various levels of research conferences were also exhibited to a moderate extent. However, the table also showed that it was difficult for teachers to publish action researches about determined school's identified priority areas because of budget constraints.

\section{3) Community Service}

The extent of commitment and responsiveness of the respondents with regards to community service remained to be on a moderate extent because of difficulty in attaining quality work-life balance. Nevertheless, they still inform leaners, parents and community in implementing banner programs and encourage learners to apply classroom learning in home and in community to a great extent.

Consequently, they already made their realization on the importance of disseminating factual information and extending help and assistance to a great extent. Commitment was very evident as they inform learners and parents in implementing banner programs and encourage learners to apply classroom learning at home and in community.

On the other hand, other areas like sharing information of school events and achievements to the community through social media websites and involving home and community in sharing accountability for learners' achievement were only on a moderate extent. Furthermore, they sometimes assists officials of the community in implementing programs, extend assistance to other civic clubs, provide support on different community projects, use of community for teaching and learning with proper coordination and share innovation and best practices to the people in the area as reflected on the gathered data.

\section{Association of the respondent's profile variables and their commitment and responsiveness}

Association of Training and Development Attended and Commitment and Responsiveness in Instruction, Research and Community Service. The data revealed that instruction depends 
on training and development while research depends on the number of membership in professional organization. This is best explained by the idea that the more trainings attended by the teachers, the more they become updated with new insights in the teaching-learning process thus, resulting to improved skills, knowledge and attitude of the teachers. On the other hand, more memberships in professional organization would mean strong support system that would provide quality suggestions and feedback from expert practitioners becoming a motivated research enthusiast.

Meanwhile no significant association were found between educational attainment and teaching experience to the three areas. In addition, membership to professional organization did not have significant association to instruction and community service while training and development also had no significant association to research and community service.

\section{Opportunities and prospects for individual and organizational growth}

The data indicated that English teachers themselves strongly agree on the opportunities and prospects for individual and organizational growth. When it comes to individual growth, an organized career development program would cultivate mindset of the faculty, open doors for varied scholarships, develop holistic personal development and lead to increase benefits. They also show strong agreement on having extended role teaching, adding more membership in professional organization and receiving recognitions as a performing teacher.

On the other hand, strong agreement was also exhibited in terms of organizational growth. When prioritized, it would result to committed and dedicated employees who are productive members of the workforce. Another is sustained technical assistance, harmonious relationship among other teachers and continuous learning initiatives. Significantly, it would intensify improved delivery of basic services.

\section{E. Issues and challenges related to career development}

Teachers strongly agree that there are existing issues and challenges when it comes to career development. Most rampant among the issues and challenges is the time for professional learning. Additionally, other issues that arise include work environment and colleagues, attendance in training for further growth and quality of professional development activities.

Furthermore, the data also revealed that there is a problem on the transparency of the selection and ranking committee and awareness on the processes and requirements of reclassification. Administrative support and budget for career development are also indicated. There is also a problem on the number of workshops and conferences. This is because of limited free trainings offered to teachers.

Likewise, some more challenges focused on sustainability of financial assistance from LGU, manner of hiring, promotion and transfer, availability of scholarship grants, membership in professional organization, and publication of vacancies and number of items.

\section{F. Career development program for junior high school English teachers}

The proposed career development program is intended to help junior high school English teachers attain growth and advancement on their chosen career and envisions to sustain the culture of excellence through improved performance. Anchored from the findings of this study and based on the umbrella of quantitative and qualitative data gathered, the program was conceptualized and was directed into four main projects which have an acronym of STAR, SPG, TSCiH and LSP that offers possible solutions to address least rated area and highest rated issues and challenges on career development experienced by the teacher-respondents. These are Strengthening Teachers' Ability in Research (STAR), Solidifying Professional Growth (SPG), Teachers, School and Community in Harmony (TSCiH) and Learning Support Practices (LSP). This is expected to help teachers achieve growth and advancement in the workplace by having their own willingness and responsibility, collaboration with other professionals and extending help to the community.

\section{Conclusions}

The findings concluded that English teachers respond to the call of continuing professional development supported by their post graduate degrees although they have few related trainings and limited memberships. In addition, they show commitment and responsiveness to a great extent in instruction but only on moderate extent with regards to research and community service. The data showed that instruction depends on training and development while research depends on membership to professional organization. Furthermore, an organized and wellplanned career development program leads to individual and organizational growth. Issues and challenges occur in the workplace if the organization fails to prioritize the career growth of the teachers. The proposed career development program consists of four projects namely STAR, SPG, TSCiH and LSP which offers professional growth and advancement.

\section{Recommendations}

In the light of the findings and conclusions on which the implications and inferences were based, the following recommendations were suggested:

1. Assess the proposed career development program for possible approval and implementation of the Senior Education Program Specialist in charge of Human Resource and Development Division.

2. Find ways to attend more training and look for more memberships in professional organizations.

3. Participate in professional development activities like the conduct of educational research forum.

4. Conduct other studies related to the topic focusing on the perception of the school heads in other divisions and other regions. 
Volume-3, Issue-9, September-2020

journals.resaim.com/ijresm | ISSN (Online): 2581-5792 | RESAIM Publishing

\section{References}

[1] Archer J. (2019). Importance of a career versus a job. Retrieved from https://work.chron.com/importance-career-vs-job-2576.html

[2] Basu Mallick, C. (2019). Employee career development. Retrieved from https://www.hrtechnologist.com/articles/learningdevelopment/employee- career-development-tips-and-solutions/

[3] Craig, W. (2017). Why a strong employee/employer relationship is important. Retrieved from https://www.forbes.com/sites/williamcraig/2017/09/20/why-a- strongemployeeemployer-relationship-is-important/\#3ef783e464d 9

[4] Frost, S. (2019). The Importance of Training \& Development in the Workplace. Retrieved from

https://smallbusiness.chron.com/importance-training-developmentworkplace-10321.html
[5] Gonong, G.O. (2018). Addressing Teacher Professional Development Issues: Supporting Teacher Quality (PDF file). Retrieved from https://www.deped.gov.ph/wpcontent/uploads/2018/07/EducSummitAddressingTeacherProfessionalD evelopmentIssues.Nov2_.pdf

[6] Stevenson, M. (2019). The importance of career pathing. Retrieved from https://www.hrexchangenetwork.com/hr-talent-management/articles/theimportance-of-career-pathing

[7] Jones, G.R., George, J. M. \& Hill, C.W. (2010). Contemporary Management. Boston: Irwin McGraw Hill.

[8] Weng, Q. \& Mcelroy, J. (2010). The relationship between career growth and organizational commitment. Journal of Vocational Behavior. 77. 391-400. 